\title{
The Relationship between IL-1 $\beta$, IL-17, IL-33 and Bcl-2 and the Development of Diabetic Nephropathy
}

Ahmed Nabil ( $\sim$ drnabil_100@hotmail.com )

Beni Suef University https://orcid.org/0000-0002-5617-4726

Basant Mahmoud

Beni Suef University

Adel Abdel-Moneim

Beni Suef University

Zinab Negeem

Beni Suef University

\section{Research Article}

Keywords: Diabetic nephropathy, diabetic complications, Inflammation, Cytokines, Apoptosis

Posted Date: November 3rd, 2021

DOI: https://doi.org/10.21203/rs.3.rs-937627/v1

License: (c) (i) This work is licensed under a Creative Commons Attribution 4.0 International License. Read Full License 


\section{Abstract}

Background: Diabetic nephropathy (DN) is among the main complications of diabetes mellitus, and it has been the major factor of renal failure. The current investigation aims to address the association between beta-cell lymphoma-2 (Bcl-2), interleukin (IL)-1 $\beta$, IL-17, and IL-33 with the development of DN.

Methods: In this study, twenty healthy volunteers plus hundred patients have been signed up. According to their biochemical markers, patients were categorized into 5 groups; diabetic, chronic renal disease, diabetic chronic renal disease, end-stage renal disease, and diabetic end-stage renal disease.

Results: Our results showed a noticeable elevation in IL-1 $\beta$ and IL-17 levels and a reduce in IL-33 and Bcl-2 levels in all investigated groups relative to the healthy group. Positive correlations were reported between IL-1 $\beta$ with FBS and creatinine levels, IL-17, with $\mathrm{HbA} 1 \mathrm{c} \%$ and sodium levels. However, negative correlations were exerted between IL-33 with urea and sodium concentration, $\mathrm{Bcl} 2$ with $\mathrm{HbA} 1 \mathrm{c} \%$, and creatinine levels.

Conclusion: The present data revealed a marked relationship between Bcl-2, IL-1 $\beta$, IL-17, and IL-33 levels and the progression of DN. Therefore, understanding the molecular pathways of inflammatory and apoptotic activities-related DN could be translated into the development of therapeutic strategies.

\section{Introduction}

The main risk factor for the progression of chronic renal disease is diabetes, and diabetic nephropathy (DN) may be developed in 20 to $30 \%$ of diabetic patients and it was the main risk factor of renal failure disease [1,2]. The knowledge of the fundamental pathophysiologic mechanisms contributing to DN had been developed rapidly. Classically, renal diseases have been indicated through hemodynamic and metabolic changes [3], as well as raising blood and glomerular pressure and modifying molecules under hyperglycemia. Additionally, the main factors influence the development of DN seem to be oxidative stress, inflammation, and fibrosis [4]. The inflammatory cytokines exert an important variety of activities involved in the pathophysiology of DN, along with the earlier stages of the disease, development stage, and ESRD [5]. Pro-inflammatory cytokines can be produced from renal cells, including tumor necrosis factor- $\alpha$ (TNF- $\alpha$ ), interleukin (IL)-1, and IL-6.

Accordingly, cytokines may have several impacts on the renal systems, thereby playing a pivotal role in the development of kidney diseases [6]. However, TNF-a induces the formation of local reactive oxygen species, independent of hemodynamic pathways, leading to glomerular capillary wall changes, and thereby elevated albumin permeability [7]. Recent evidence supporting a definitive role of T-helper type 17 (Th17) cells in the etiopathogenesis of type 1 diabetes mellitus (T1DM). Moreover, IL-17 was demonstrated to have an important function in inflammation, and T2DM [8]. IL-33 has been revealed several protective properties in type 2 diabetes, obesity, and cardiovascular disease [9]. Beta-cell lymphoma-2 ( $\left.\mathrm{Bcl}_{2}\right)$, as an antiapoptotic protein, can protect the consistency of the outer membrane of mitochondria via suppressing the proapoptotic molecules [10]. Hyperglycemia can affect the various phases in the apoptotic signalling by enhancing oxidative, nitrosative stress, and promoting the proapoptotic $\mathrm{Bcl}_{2}$ family proteins as well as caspase cascade pathway [11]. Importantly, $\mathrm{Bcl}_{2}$ members remain innocuously inside the kidney cells until stimulated or suppressed by physiologic stress induced by specific nephrotoxins, or acute glomerulonephritis [12]. Thus, the assessment of the processes that underlie metabolic and inflammatory alterations that may influence the pathophysiology and progression of diabetic nephropathy has become greatly important. The present study aims to explore the association between cytokines; IL-1 $\beta$, IL-17, and IL-33 as well as an anti-apoptotic protein, $\mathrm{Bcl}_{2}$, with the development of diabetic nephropathy.

\section{Patients And Methods}

\section{Patients}


A total of 100 patients from Kidney Hospital, Beni-Suef, Egypt, were allocated according to biochemical markers into five groups (20 patients per each group); diabetic, chronic renal disease, diabetic chronic renal disease, end-stage renal disease, and diabetic end-stage renal disease. In addition, 20 healthy volunteers have been used as healthy controls in the study. The study protocol has been performed in compliance with the Helsinki declaration as well as the recommendations for good clinical practice. Blood samples were obtained during months from September 2017 to May 2018 after the study protocol was approved by the hospital ethical committee.

\section{Experimental design}

The healthy adult individuals, diabetic ( $\mathrm{HbA} 1 \mathrm{c}>6.5 \%$, creatinine $<1.5 \mathrm{mg} / \mathrm{dl})$, chronic renal disease $(\mathrm{HbA} 1 \mathrm{c}<6.0 \%$, creatinine; $>1.5-6.5 \mathrm{mg} / \mathrm{dl}$ ), diabetic chronic renal disease (HbA1c > 6.5\%, creatinine; > 1.5- $6.5 \mathrm{mg} / \mathrm{dl}$ ), end-stage renal disease (hemodialysis patients) (HbA1c $<6.0 \%$, creatinine; $>6.5 \mathrm{mg} / \mathrm{dl}$ ), and diabetic hemodialysis patients ( $\mathrm{HbA} 1 \mathrm{c}>6.5 \%$, creatinine; $>6.5 \mathrm{mg} / \mathrm{dl}$ ) have been allowed to enroll in the study. However, key exclusion criteria include thyroid dysfunction, respiratory disorder, liver dysfunction, cerebrovascular diseases, ischemic heart disease, autoimmune disorders, allergies, pregnancy and lactating women, and patients with medical conditions including, infections, malignancies. Enrolled patients and healthy participants have been allocated into 6 groups (20 patients per each group); Group 1 Healthy controls, Group 2 consisted of diabetic patients, Group 3 had patients with chronic renal disease, Group 4 had patients with diabetic chronic renal disease, and Group 5 included patients with end-stage renal disease, and Group 6 had patients with diabetic end-stage renal disease.

\section{Laboratory investigations}

Blood samples were collected from individuals after overnight fasting through plain and EDTA tubes (4ml each). EDTA samples have been used for the detection of $\mathrm{HbA} 1 \mathrm{C} \%$ and cytokines mRNA expression. Until used for assay, samples were kept at $-80^{\circ} \mathrm{C}$. Blood sugar, creatinine, uric acid, urea, sodium, and potassium levels have been assessed by kits obtained from SPINREACT, Spain. Glycosylated hemoglobin ( $\mathrm{HbA1c} \%$ ) has been measured by kits obtained from MyBiosource (San Diego, CA, USA). IL-1 $\beta$ and IL-17 were estimated using ELISA Kit. According to the kit instructions given, the procedures were performed.

\section{Isolating RNA and qRT-PCR analysis}

Total IL-37 RNA was isolated from the blood samples by using Qiagen tissue extraction kit purchased from Qiagen, Germany, then the target DNA sequences were amplified on step one plus PCR using method of multiplex polymerase chain reaction (PCR). Furthsr, $2 \mu \mathrm{g}$ RNA was used to produce Complementary DNAs (cDNAs) which were amplified by SYBR Green master mix (Thermo Fisher Scientific, USA), using the primer sets. The primer sequences for IL-33 were F:

5'ACAGAATACTGAAAAATGAAGCC-3' R:5'CTTCTCCAGTGGTAGCATTTG-3'; (NM001314046.1); Bcl2:F: 5AGATGTCCAGCCAGCTGCACCTGAC3 and R: 5AGATAGGCACCCAGGGTGATGCAAGCT-3 (M13994); $\beta$-actin $\mathrm{F}$ : 5CTGTCTGGCGGCACCACCAT-3 R: 5-GCAACTAAGTCATAGTCCGC-3 (X00 351). By using the manufacturer's program, the amplified data collected were determined according to the methods of Livak and Schmittgen [13], and the results were normalized to $\beta$-actin.

\section{IL-17 gene polymorphism by real time-PCR:}

The Qia-amplification DNA extraction kit has been used to extract DNA from the whole blood (Qiagen, USA). DNA quantitation and purity measurement were carried out in the collected DNA samples by the NanoDrop® (ND)-1000 
spectrophotometer (NanoDrop Technologies, Inc., USA). Genotyping of miRNA 499 (rs3746444) SNP has been conducted by

RT- PCR with TaqMan allelic discrimination assay (Applied Biosystems, USA).

\section{Statistical Analysis}

The current results were interpreted employing statistical software (SPSS) (version 22.0, Chicago, IL, USA). A one-way variance analysis (ANOVA) was performed to compare the data across intervention groups, followed by Duncan test to assess the significant differences between groups. Pearson's method for estimating the degree of dependency between variables was used as simple linear correlation analysis. Statistically, $P<0.05$ value is deemed significant.

\section{Results}

Our results showed a marked $(P<0.001)$ elevation in the levels of serum creatinine and uric acid as well as blood urea in the groups of; chronic renal disease, diabetic chronic renal disease, end-stage renal disease, and diabetic end-stage renal disease relative to the healthy group. Furthermore, FBS and $\mathrm{HbA} 1 \mathrm{c} \%$ levels have been increased markedly $(\mathrm{P}<0.001)$ in diabetic groups relative to the healthy group. Potassium levels exhibited a marked increase in chronic renal disease, end-stage renal disease, and diabetic end-stage renal disease groups relative to healthy controls.

The obtained data also revealed a noticeable $(P<0.001)$ elevation in the levels of IL-1 $\beta$ and IL-17 in all investigated groups compared to the healthy group. However, IL-33 and $\mathrm{Bcl}_{2}$ mRNA expressions revealed a significant $(\mathrm{P}<0.001)$ down-regulation in the investigated groups relative to healthy controls (Fig. 1). Our results revealed that the frequencies of the A/A genotype recorded $55.0 \%, 55.0 \%, 55.0 \%, 45.0 \%, 50.0 \%$, and $50.0 \%$ in healthy controls, diabetic, chronic renal disease, diabetic chronic renal disease, end-stage renal disease, and diabetic end-stage renal disease groups, respectively. Also, the $\mathrm{G} / \mathrm{G}$ genotype recorded high frequencies in chronic renal disease and end-stage renal disease groups compared to the healthy group, recording $20.0 \%$ in both groups. Regarding diabetic groups; diabetic, diabetic chronic renal disease, and diabetic end-stage renal disease groups have been recorded $5.0 \%, 10.0 \%$, and $10.0 \%$, respectively in the $\mathrm{G} / \mathrm{G}$ genotype. On the other hand, the A/G genotype frequencies were highly in diabetic groups; diabetic, diabetic chronic renal disease and diabetic end-stage renal disease groups $40.0 \%, 45.0 \%$, and $40.0 \%$, respectively, while chronic renal disease and end-stage renal disease groups recorded $25.0 \%$ and $30.0 \% \%$, respectively (Table. 1 ).

\section{Table 1}

Biochemical parameters and interleukin-17 genotyping in healthy controls, diabetic and renal disease groups. 


\begin{tabular}{|c|c|c|c|c|c|c|}
\hline $\begin{array}{l}\text { Group } \\
\text { Parameter }\end{array}$ & $\begin{array}{l}\text { Healthy } \\
\text { controls }\end{array}$ & Diabetic & $\begin{array}{l}\text { Chronic renal } \\
\text { disease }\end{array}$ & $\begin{array}{l}\text { Diabetic } \\
\text { chronic renal } \\
\text { disease }\end{array}$ & $\begin{array}{l}\text { End-stage } \\
\text { renal } \\
\text { disease }\end{array}$ & $\begin{array}{l}\text { Diabetic end- } \\
\text { stage renal } \\
\text { disease }\end{array}$ \\
\hline FBS (mg/dl) & $92.01 \pm 2.09^{a}$ & $194.65 \pm 15.32^{c}$ & $87.25 \pm 1.92^{\mathrm{a}}$ & $189.25 \pm 14.09^{c}$ & $87.75 \pm 2.58^{a}$ & $133.75 \pm 9.92^{b}$ \\
\hline HbA1c (\%) & $4.87 \pm 0.53^{\mathrm{a}}$ & $8.55 \pm 0.37^{d}$ & $4.99 \pm 0.09^{a}$ & $6.99 \pm 0.15^{\mathrm{c}}$ & $4.94 \pm 0.11^{\mathrm{a}}$ & $6.58 \pm 0.16^{b}$ \\
\hline $\begin{array}{l}\text { Creatinine } \\
(\mathrm{mg} / \mathrm{dl})\end{array}$ & $1.01 \pm 0.02^{\mathrm{a}}$ & $1.12 \pm 0.03^{\mathrm{a}}$ & $2.46 \pm 0.19^{b}$ & $2.55 \pm 0.15^{b}$ & $8.10 \pm 0.29^{c}$ & $8.38 \pm 0.37^{c}$ \\
\hline Urea (mg/dl) & $27.19 \pm 1.14^{a}$ & $33.16 \pm 1.72^{\mathrm{a}}$ & $71.25 \pm 2.54^{\mathrm{c}}$ & $58.84 \pm 1.26^{b}$ & $128.65 \pm 7.43^{e}$ & $113.70 \pm 4.34^{\mathrm{d}}$ \\
\hline $\begin{array}{l}\text { Uric acid } \\
(\mathrm{mg} / \mathrm{dl})\end{array}$ & $4.45 \pm 0.28^{a}$ & $4.54 \pm 0.31^{a}$ & $6.68 \pm 0.13^{b}$ & $5.98 \pm 0.14^{b}$ & $6.64 \pm 0.24^{b}$ & $6.44 \pm 0.25^{b}$ \\
\hline Sodium (mEq/l) & $139.25 \pm 1.34^{\mathrm{ab}}$ & $142.90 \pm 1.18^{b}$ & $158.53 \pm 0.92^{d}$ & $155.30 \pm 2.01^{d}$ & $148.30 \pm 2.64^{c}$ & $135.48 \pm 1.46^{a}$ \\
\hline $\begin{array}{l}\text { Potassium } \\
(\mathrm{mEq} / \mathrm{l})\end{array}$ & $4.31 \pm 0.11^{\mathrm{a}}$ & $4.40 \pm 0.13^{\mathrm{a}}$ & $5.98 \pm 0.11^{\mathrm{bc}}$ & $4.50 \pm 0.17^{a}$ & $6.25 \pm 0.11^{c}$ & $5.64 \pm 0.19^{b}$ \\
\hline \multicolumn{7}{|l|}{ IL-17Genotype } \\
\hline $\mathrm{AA}(\%)$ & 55 & 55 & 55 & 45 & 50 & 50 \\
\hline GG (\%) & 10 & 5 & 20 & 10 & 20 & 10 \\
\hline AG (\%) & 35 & 40 & 25 & 45 & 30 & 40 \\
\hline
\end{tabular}

Data were expressed as mean \pm standard error. Means that have the same superscript symbol (s) would not differ significantly. FBS: fasting blood sugar, IL-17: interleukin-17.

Among diabetic renal dysfunction groups, IL-1 $\beta$ showed a positive correlation with creatinine $(r=0.415, P<0.05)$, and FBS ( $r$ $=-0.432 ; P<0.05)$. Also, IL-17 was correlated positively with HbA1c\% $(r=0.463 ; P<0.01)$, and Sodium $(r=-0.418 ; P<0.05)$. On the other hand, IL-33 was correlated negatively with urea $(r=-0.487 ; P<0.01)$ and with sodium $(r=-0.631, P<0.001)$. In addition, our findings revealed a negative correlation between Bcl-2 with creatinine $(r=0.426, P<0.05)$, and $\mathrm{HbA} 1 \mathrm{c} \%(r=$ $-0.411, \mathrm{P}<0.05)$ (Fig. 2, 3).

\section{Discussion}

The major long term microvascular disorder of diabetes is DN. The current data revealed an obvious elevation in serum creatinine and urea levels in the renal disease groups compared to the healthy group. Also, FBS and $\mathrm{HbA} 1 \mathrm{c} \%$ recorded a marked higher levels in diabetic groups relative to healthy controls. Several researchers indicated that hyperglycemia and pro-inflammatory cytokines have a crucial role in the pathophysiology of DN. Notably, IL-1 $\beta$ is thought to enhance proliferation of mesangial cell, and matrix deposition [14] and plays a pivotal function in several diseases, including diabetes and atherosclerosis [15]. Our study revealed that IL-1 $\beta$ level has been increased noticeably in all diabetic and renal disease groups and these finding was in parallel with Osborn et al. [16] who reported a correlation between the elevation in IL-1 $\beta$ levels with insulin secretion impairment, cell proliferation inhibition, and pancreatic $\beta$-cells apoptosis. Moreover, IL-1 $\beta$ neutralizing antibody administration substantially decreases HBA1c\% and enhances the role of islets in HFD-induced diabetic mice. Regarding the diabetic end-stage renal disease group, our results revealed a noticeable positive correlation between IL-1 $\beta$ with FBS and creatinine levels. These data were consistent with Lei et al. [17] who reported that IL-1 is esential to enhance the onset and development of diabetic renal disease, and is involved also in intraglomerular hemodynamics abnormalities [18]. Additionally, Timoshenko et al. [19] revealed a significant role of IL-1 $\beta$ in murine model of crescentic glomerulonephritis where IL-1 $\beta$ has a significant impact on cellular effectors in glomeruli and glomerular injury mechanisms. Further, Palsamy and Subramanian [20] revealed that IL-1 $\beta$ with TNF-a may induce iNOS expression in glomerular mesangial cells, resulting in large amounts of NO production, leading to hyperfiltration and higher 
microalbuminuria. In this regard, IL-1 $\beta$ promotes progression of renal disease in chronic diabetic patients and could therefore be a potential therapeutic target for alleviate or delay DN.

In the pathogenesis of several inflammatory disorders, the role of IL-17 is well reported, but further studies are needed to explore its contribution in DN. In the present study, our finding observed a noticeable increase in serum IL-17 level in diabetic and renal groups relative to healthy controls. Chen et al. [21] mentioned that levels of serum IL-17 in newly diagnosed patients with T2DM have been markedly increased compared to healthy subjects. Also, several investigations showed that IL17 had a central role in T2DM inflammation and complications [8]. Interestingly, IL-17 activates the pathway of NF-KB [22] which induces pro-inflammatory cytokines expressions including, IL-1 $\beta$, IL-6, TNF-a, and adhesion molecules, thereby initiate the destruction of several tissues [23]. Moreover, IL-17 increases TNF-a up-regulation and chemokine (C-C motif) ligand-2 in tubular epithelial and mesangial cells, leading to recruit local macrophages [24]. In diabetic mice, IL-17 mediates podocyte lesion, mesangial expansion, and kidney fibrosis in DN animal model [25]. Moreover, activation of the IL-17A/NF-KB pathway may lead to diabetic renal inflammation. Among the diabetic end-stage renal disease group, our results showed a positive correlation between IL-17 with both $\mathrm{HbA} 1 \mathrm{c} \%$ and sodium concentration. Cytokines, including TGF- $\beta 1$, TNF-a, Interferongamma, IL-17A, and IL-1 $\beta$, can be control hypertension by influencing endothelial dysfunction, the equilibrium between water and salts, and sympathetic regulation [26]. IL-17A could directly stimulate endothelial dysfunction-associated hypertension, as seen in transgenic mice overexpress IL-17A in keratinocytes [27] In IL-17A deficient mice, alterations in endotheliumdependent vasodilatation phenylephrine-induced contraction caused by Angll, and reactive oxygen species generation was inhibited $[28,29]$. However, sodium transporters and nephron expression and activities were modulated by IL-17A. Interestingly, IL-17A depletion has eliminated distal tubule transporter activation, in particular, the sodium-chloride cotransporter, the epithelial sodium channel, and decreased renal damage caused by Angll [30]. By controlling activation, IL-17A significantly contributes to the etiopathogenesis of kidney fibrosis, T cell expression, and inflammatory-mediated cell infiltration [31]. With modern clinical trials, the area of anti-IL-17A antibodies in treated different diseases has recently increased significantly. Thus, targeting the IL-17 pathway can reflect a novel therapeutic strategy in managing the progression of DN.

The relation of SNPs inside the IL-17 family's genes and a number of diseases was investigated recently, however, few studies have discussed their impact on kidney diseases. Kim et al. [32] recorded a marked correlation between the IL17RA rs4819554 A allele with end-stage renal disease patients. Besides, Coto et al. [33] reported a correlation between abnormal kidney function and SNP rs4819554 in the IL17RA promoter region. Regarding our knowledge, this is the first study to investigate the polymorphisms of IL-17 gene in the progression and development of DN. Our data showed a higher frequency of the heterozygous $A / G$ polymorphism in diabetic groups, while non-diabetic renal dysfunction groups showed a higher frequency of homozygote G/G as compared to healthy controls. These findings suggest that the IL 17 GG and AG genotype may be linked with the severity of the disease. Moreover, the molecular importance of IL-17A genotype with increased IL-17 production in persons with the A allele was supported by our results. Accordingly, Linhartova et al. [34] mentioned that variability of the IL-17A gene can partially affect T1DM management in diabetic patients.

Concerning IL-33, our results revealed a significant reduction in diabetic and renal disease groups relative to healthy controls. Duan et al. [35] mentioned that the expression of IL-33 has been markedly higher in patients without kidney damage. Among the diabetic chronic renal disease group, the current results exert a negative correlation between IL-33 with urea and sodium levels. Our findings were consistent with previous reports that explained the vital relation between IL-33 and the progression of renal diseases [36]. Moreover, IL-2 and IL-33 together were protected against metabolic syndrome diseases, albuminuria, and polarize macrophages to alternatively activated macrophages (M2) phenotype [37]. Recently, Stremska et al. [38] reported that IL-33 has a central role in facilitating Treg responses, therefore IL-33 and IL-2 may synergize to improve Tregs and can also protect against experimental acute kidney damage. On the contrary, Nile et al. [39] reported that IL-33 has been observed to be an endogenous "danger signal" or "alarm" for trigger the immune response for responding to hypersensitive disease, which indicate that IL-33 may act as a dual-function. In addition, In diabetic nephropathy, the rise in IL-33 levels is 
not associated with kidney damage, but the elevation may a result of diabetes [40]. Importantly, there is also a need to fully elucidate the processes underlining the association of IL-33 with diabetic renal disease.

In this study, it has been demonstrated that Bcl2 mRNA expression decreased in all diabetic and renal disease groups relative to the healthy group. Our results were in compatible with Cipollone et al. [41] who proved that Bcl2 expression has been substantially decreased in microalbuminuric diabetic patients as a result of elevation in oxidant load due to hyperglycemia. In addition, Bcl-2 downregulation leads to stimulation of the NF-kB route, thereby the progression of nephropathy. Almond and Cohen [42] reported that some Bcl2 family has been found to suppress apoptotic death by regulating the activation of caspases and mitochondrial membrane permeability [43]. Notably, Bcl2 protein accumulation may occur via the signalling of mitogen-activated protein kinases and is a cause of intrinsic apoptotic events, with activation of apoptotic protease factor-1

and initiator caspase-9, accompanied by activation of -3 and -7 executioner caspases, cell death, and further renal injury [44]. Concerning diabetic chronic kidney disease patients, the current findings exert a negative correlation between Bcl2 with creatinine and $\mathrm{HBA} 1 \mathrm{C} \%$. These results have been consistent with the finding of Majewska et al. [45] who found a decrease in the expression of $\mathrm{Bcl} 2$ in end-stage renal disease patients compared to controls. This elevation of apoptosis may be a result of higher Bcl2-antagonist/killer and reduced Bcl2 expression. The decreased Bcl2 expression has been hypothesised to be a crucial factor for the inability of uremic lymphocytes for relieving apoptosis [46]. Our findings support the concept that apoptosis route (by decrease $\mathrm{Bcl} 2$ ) is a pathogenic process of kidney injury induced by diabetic inflammation mechanisms. Additionally, understanding the role of IL-1 $\beta, I L-17, I L-33$, and Bcl 2 in diabetic patients can help in the early identification of individuals at risk of DN. Therefore, IL-1 $\beta$, IL-17, IL-33, and Bcl2 are novel effective therapeutic goals for diabetic complications management.

The limitations of this study may be related to the sample size of each group, data on medications in detail, physical activity, and smoking screening. In addition, the limitations of examined some investigations such as eGFR, a number of the novel cytokines-associated with renal diseases.

\section{Conclusion}

The study revealed that the diabetic renal disease groups showed increased levels of IL-1 $\beta$, IL-17, with reduced in IL-33, Bcl2 levels relative to healthy controls. Therefore, the association of these molecular with inflammatory and apoptotic activitiesassociated diabetic nephropathy was important for understanding the onset and progression of the disease. Additionally, further prospective studies in a large cohort are necessary to better explore the causality question in order to translate into the development of anti-inflammatory therapeutic strategies for diabetic nephropathy.

\section{Declarations}

\section{Competing interests}

The authors declare that they have no competing interests.

\section{Funding}

The study did not receive any funding.

\section{Ethics approval and consent to participate}

The research protocol was approved by the hospital ethical committee in compliance with the Declaration of Helsinki and the recommendations for good clinical practice (BSU/2018/7). Written informed consent was given by all participants in the study. 


\section{Availability of data and materials}

All data generated or analyzed in this study are included in this published article.

\section{Authors' contributions}

All authors contributed to the study's conception and design. Data collection, material preparation, and analysis were performed by Basant Mahmoud, Adel Abdel-Moneim, and Zinab Negeem. The draft of the article was written by Basant Mahmoud, Adel Abdel-Moneim, Zinab Negeem, and Ahmed Nabil. All authors read and approved the final manuscript.

\section{Consent for publication}

All authors approved and consented to publish the presented results.

\section{References}

1. Shahbazian H, Rezaii I. Diabetic kidney disease; review of the current knowledge. J Renal Inj Prev. 2013; 2(2): 73-80.

2. Bouaziz A, Zidi I, Zidi N, Mnif W, Zinelabidine HT. Nephropathy following type 2 diabetes mellitus in Tunisian population. West Indian Med J. 2012; 61: 881-889.

3. Taha H, Mahmoud HH, Soliman AS, Taha MM, Mohammed RA. The Association between Highly Sensitive C-Reactive Protein and Interleukin-18 with Nephropathy in a Sample of Type 1 Diabetic Egyptian Patients Med J Cairo Univ. 2019; 87(4): 2393-2402.

4. Qin J, Peng Z, Yuan Q, Li Q, et al. AKF-PD alleviates diabetic nephropathy via blocking the RAGE/AGEs/NOX and PKC/NOX Pathways. Sci Rep. 2019; 9(1):4407.

5. Donate-Correa J, Martín-Núñez E, Muros-de-Fuentes M, Mora-Fernández C, Navarro- González J F. Inflammatory cytokines in diabetic nephropathy. J Diabetes Res. 2015: ID 948417.

6. Donate-Correa J, Víctor G, Tagua VG, et al. Pentoxifylline for Renal Protection in Diabetic Kidney Disease. A Model of Old Drugs for New Horizons. J Clin Med. 2019; 8, 287.

7. García-García PM, Getino-Melián, MA, Domínguez-Pimentel V, Navarro-González J F. Inflammation in diabetic kidney disease. World J Diabetes 2014; 5(4): 431-443.

8. Abdel-Moneim A, Bakery HH, Allam G. The potential pathogenic role of IL-17/Th17 cells in both type 1 and type 2 diabetes mellitus. Biomed Pharmacother. 2018; 101: 287-292.

9. Miller AM. Role of IL-33 in inflammation and disease. J Inflamm (Lond). 2011;8(1):22.

10. Opferman JT, Kothari A. Anti-apoptotic BCL-2 family members in development. Cell Death Differ .2018; 25: 37-45.

11. Anuradha R, Saraswati M, Kumar KG, Rani, SH. Apoptosis of Beta Cells in Diabetes Mellitus. DNA. Cell Biol. 2014; 33(11):743-748.

12. Borkan SC. The Role of BCL-2 Family Members in Acute Kidney Injury. Semin Nephrol. 2016;36 (3): 237-250.

13. Livak KJ, Schmittgen TD. Analysis of relative gene expression data using real-time quantitative PCR and the 2(-Delta Delta C(T)) method. Methods. 2001;25(4): 402-408.

14. Rivero A, Mora C, Muros M, Garcia J, Herrera H, Navarro-Gonzalez JF. Pathogenic perspectives for the role of inflammation in diabetic nephropathy. Clin Sci (Lond). 2009;116:479-492.

15. Maedler K, Dharmadhikari G, Schumann DM, Størling J. Interleukin-1 beta targeted therapy for type 2 diabetes. Expert Biol Ther. 2009; 9(9):1177-1188.

16. Osborn O, Brownell SE, Sanchez-Alavez M, Salomon D, Gram H, Bartfai T. Treatment with an Interleukin 1 beta antibody improves glycemic control in diet-induced obesity. Cytokine 2008; 44(1):141-148. 
17. Lei Y, Devarapu SK, Motrapu M, et al. Interleukin-1 $\beta$ Inhibition for Chronic Kidney Disease in Obese Mice With Type 2 Diabetes. Front Immunol. 2019;10:1223. doi:10.3389/fimmu.2019.01223

18. Navarro JF, Mora-Fernandez C. The role of TNF-a in diabetic nephropathy: pathogenic and therapeutic implications. Cytokine Growth FR. 2006; 17(6): 441-450.

19. Timoshanko JR, Kitching AR, Iwakura Y, Holdsworth SR, Tipping PG. Contributions of IL-1 $\beta$ and ILa-1to Crescentic Glomerulonephritis in Mice. J Am Soc Nephrol. 2003; 15: 910-918.

20. Palsamy P, Subramanian S. Resveratrol protects diabetic kidney by attenuating hyperglycemia- mediated oxidative stress and renal inflammatory cytokines via Nrf2-Keap1 signaling. Biochimica Biophysica Acta 2011;1812(7):719-731.

21. Chen C, Shao Y, Wu X, Huang C, Lu, W. Elevated Interleukin-17 Levels in Patients with Newly Diagnosed Type 2 Diabetes Mellitus. Biochem Physiol. 2016; 5: 206-217.

22. Cruz JA, Child EE, Amatya N, et al. Interleukin-17 signaling triggers degradation of the constitutive NF-KB inhibitor ABIN1. Immunohorizons. 2017;1(7): 133-141.

23. Miljkovic D, Trajkovic V. Inducible nitric oxide synthase activation by interleukin-17. Cytokine Growth FR. 2004;15(1): 2132.

24. Iyoda M, Shibata T, Kawaguchi M, et al. IL-17A and IL-17F stimulate chemokines via MAPK pathways (ERK1/2 and p38 but not JNK) in mouse cultured mesangial cells: synergy with TNF-alpha and IL-1beta. Am J Physiol Renal Physiol. 2010; 298:779-787.

25. Ma J, Li YJ, Chen X, Kwan T, Chadban SJ, Wu H. Interleukin 17A promotes diabetic kidney injury. Sci Rep. 2019;9(1):2264.

26. Wen Y, Crowley SD. Renal effects of cytokines in hypertension. Curr Opin Nephrol Hypertens. 2018; 27 (2):70-76.

27. Karbach S, Croxford AL, Oelze M, et al. Interleukin 17 drives vascular inflammation, endothelial dysfunction, and arterial hypertension in psoriasis-like skin disease. Arterioscler Thromb Vasc Biol. 2014; 34 (12), 2658-2668.

28. Madhur MS, Lob HE, McCann LA, et al. Interleukin 17 promotes angiotensin II-induced hypertension and vascular dysfunction. Hypertension 2010; 55 (2): 500-507.

29. Nguyen H, Chiasson VL, Chatterjee P, Kopriva SE, Young KJ, Mitchell BM. Interleukin-17 causes Rho-kinase-mediated endothelial dysfunction and hypertension. Cardiovasc Res. 2013; 97 (4): 696-704.

30. Norlander AE, Saleh MA, Kamat NV, et al. Interleukin-17A regulates renal sodium transporters and renal injury in angiotensin Il-induced hypertension. Hypertension 2016; 68 (1):167-174.

31. Peng X, Xiao Z, Zhang J, Li Y, Dong Y, Du J. IL-17A produced by both $\mathbf{\gamma} \mathbf{6} T$ and Th17 cells promotes renal fibrosis via RANTES-mediated leukocyte infiltration after renal obstruction J Pathol. 2015; 235(1): 79-89.

32. Kim YG, Kim EY, Ihm CG, et al. Gene polymorphisms of interleukin-17 and interleukin-17 receptor are associated with endstage kidney disease. Am J Nephrol. 2012; 36:472-477.

33. Coto E, Gómez J, Suárez B, et al. Association between the IL17RA rs4819554 polymorphism and reduced renal filtration rate in the Spanish RENASTUR cohort. Hum Immunol. 2015;1:4.

34. Linhartova PB, Kastovsky J, Lucanova S, et al. Interleukin-17A Gene Variability in Patients with Type 1 Diabetes Mellitus and Chronic Periodontitis: Its Correlation with IL-17 Levels and the Occurrence of Periodontopathic Bacteria. Mediators Inflamm. 2016: ID 2979846.

35. Duan L, Huang Y, Su Q, et al. Potential of IL-33 for Preventing the Kidney Injury via Regulating the Lipid Metabolism in Gout Patients J Diabetes Res. 2016: ID 1028401.

36. Ferhat M, Robin A, Giraud S, et al. Endogenous IL-33 Contributes to Kidney Ischemia Reperfusion Injury as an Alarmin. J Am Soc Nephrol. 2018; 29: 1272-1288.

37. Sabapathy V, Stremska ME, Mohammad S, Corey RL, Sharma PR, Sharma R. Novel Immuno modulatory Cytokine Regulates Inflammation, Diabetes, and Obesity to Protect From Diabetic Nephropathy. Front Pharmacol. 2019; 10:572. 
38. Stremska ME, Jose S, Sabapathy V, et al. IL233, a novel IL-2 and IL-33 hybrid cytokine, ameliorates renal injury. J Am Soc Nephrol. 2017; 28:2681-2693.

39. Nile CJ, Barksby E, Jitprasertwong P, Preshaw PM, Taylor JJ. Expression and regulation of interleukin-33 in human monocytes. Immunology 2010; 130 (2): 172-180.

40. Caner S, Usluoğulları CA, Balkan F, Büyükcam F, Kaya C, Saçıkara M, Koca C, Ersoy R, Çakır B. Is IL-33 useful to detect early stage of renal failure? Ren Fail. 2014;36(1):78-80.

41. Cipollone F, Chiarelli A, lezzi ML, et al. Relationship between reduced bcl-2 expression in circulating mononuclear cells and early nephropathy in type 1 diabetes. Int J Immunopathol Pharmacol. 2005; 18(4): 625-635.

42. Almond JB, Cohen GM. The proteasome: a novel target for cancer chemotherapy. Leukemia 2002; 16(4): 433-443.

43. Elmore S. Apoptosis: a review of programmed cell death. Toxicol Pathol. 2007; 35(4): 495-516.

44. Bălăşescu E, Cioplea M, Brînzea A, Nedelcu R, Zurac S, Ion DA. Immunohistochemical Aspects of Cell Death in Diabetic Nephropathy. Rom J Intern Med. 2016; 54(1): 54-62.

45. Majewska E, Baj Z, Sulowska Z, Rysz J, Luciak M. Effects of uremia and hemodialysis on neutrophil apoptosis and expression of apoptosis related proteins. Nephrol Dial Transplant 2003;18 (12): 2582-2588.

46. Dounousi E, Koliousi E, Papagianni A, et al. Mononuclear Leukocyte Apoptosis and Inflammatory Markers in Patients with Chronic Kidney Disease. Am J Nephrol. 2012; 36:531-536.

\section{Figures}



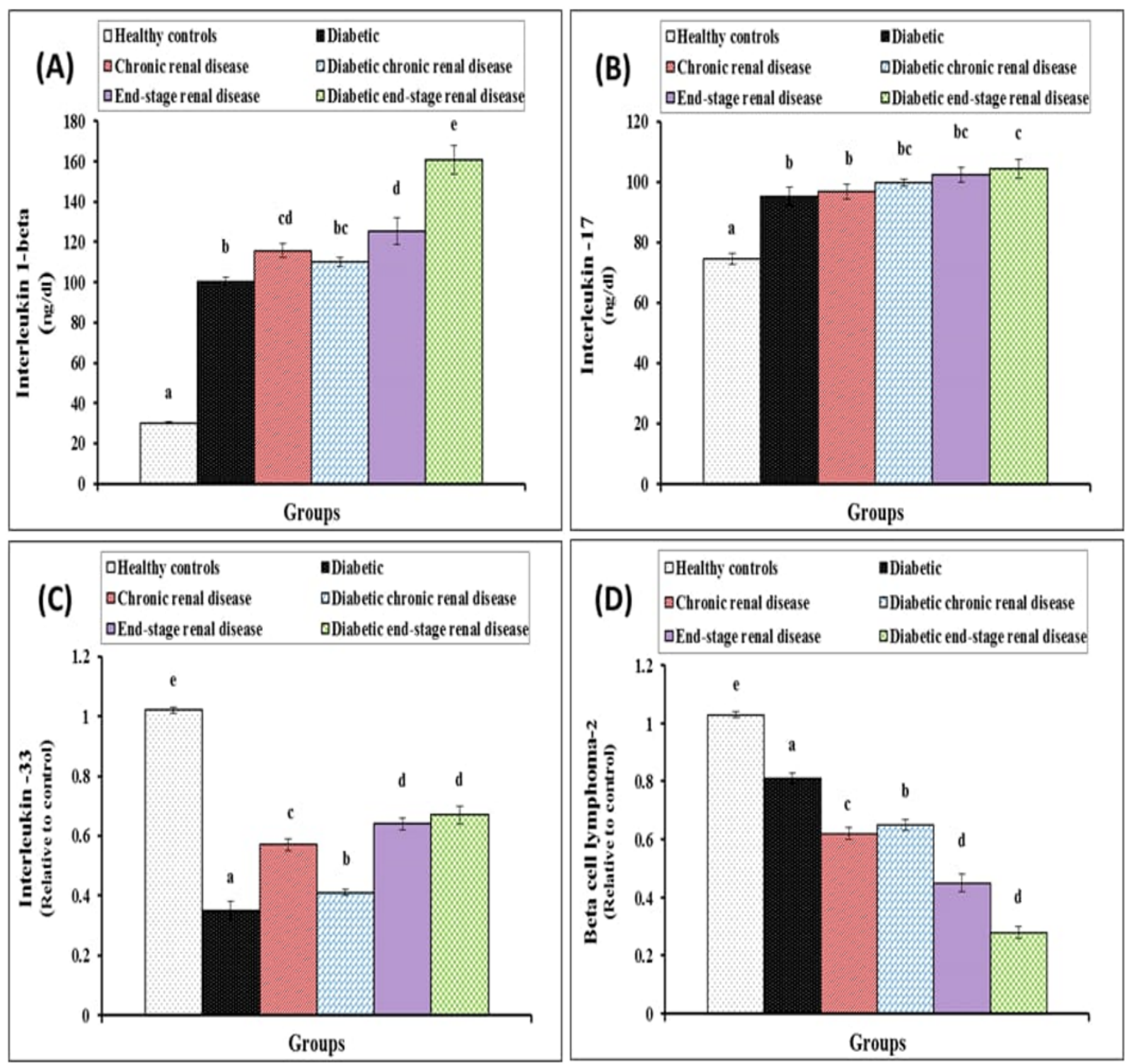

\section{Figure 1}

(A) interleukin 1-beta, (B) interleukin-17, (C) interleukin-33, (D) beta-cell lymphoma-2 levels in healthy controls, diabetic, and renal disease groups. Results were expressed as mean \pm standard error. Means that have the same superscript symbol (s) would not differ significantly. 

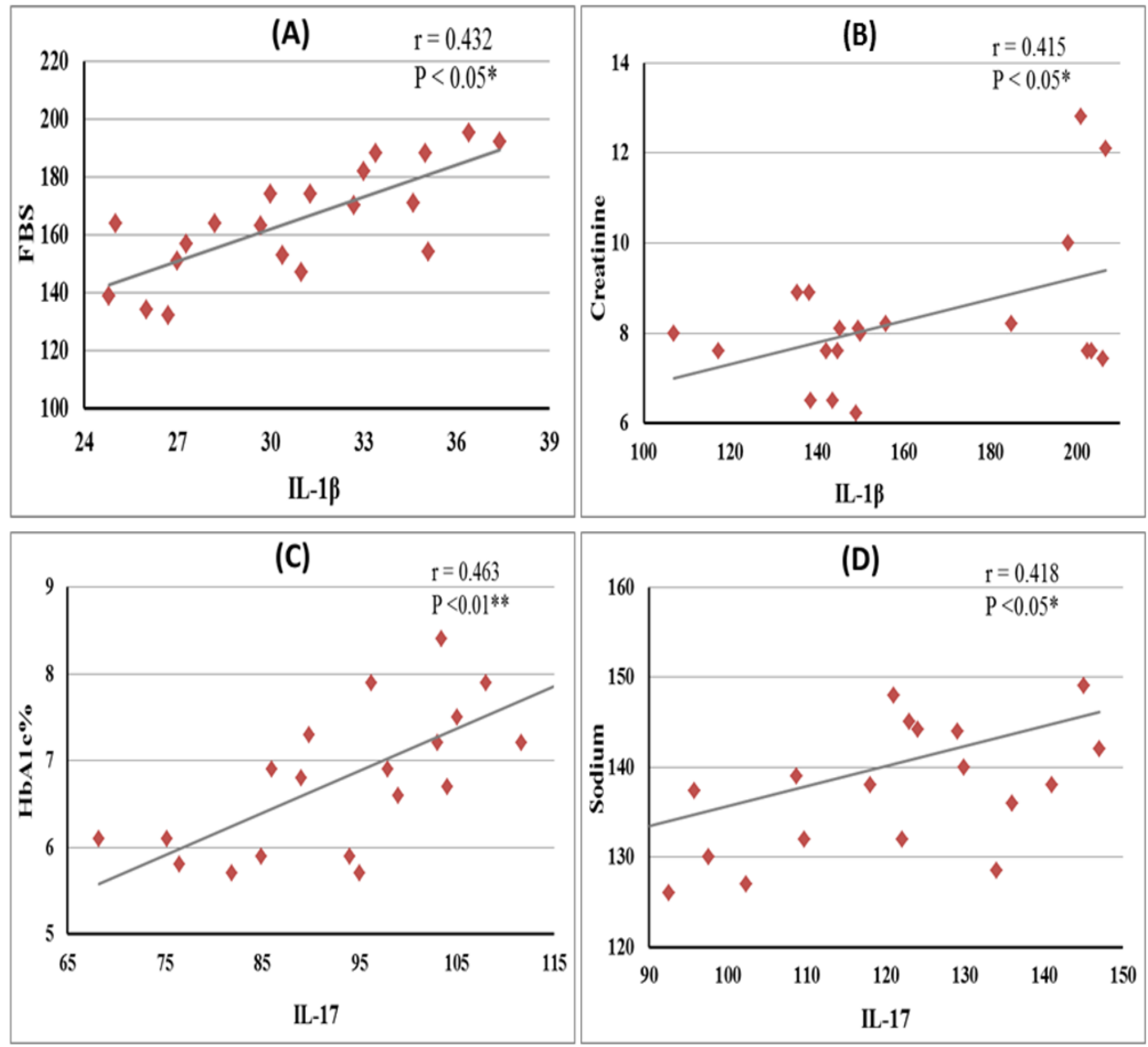

Figure 2

The correlation between fasting blood sugar with interleukin 1-beta (A) creatinine with interleukin 1-beta (B) glycated hemoglobin with interleukin-17 (C) sodium with interleukin-17 (D) in diabetic renal disease groups. Correlation is significant *at $\mathrm{P}>0.05$ level, ** at $\mathrm{P}>0.01$ level. 

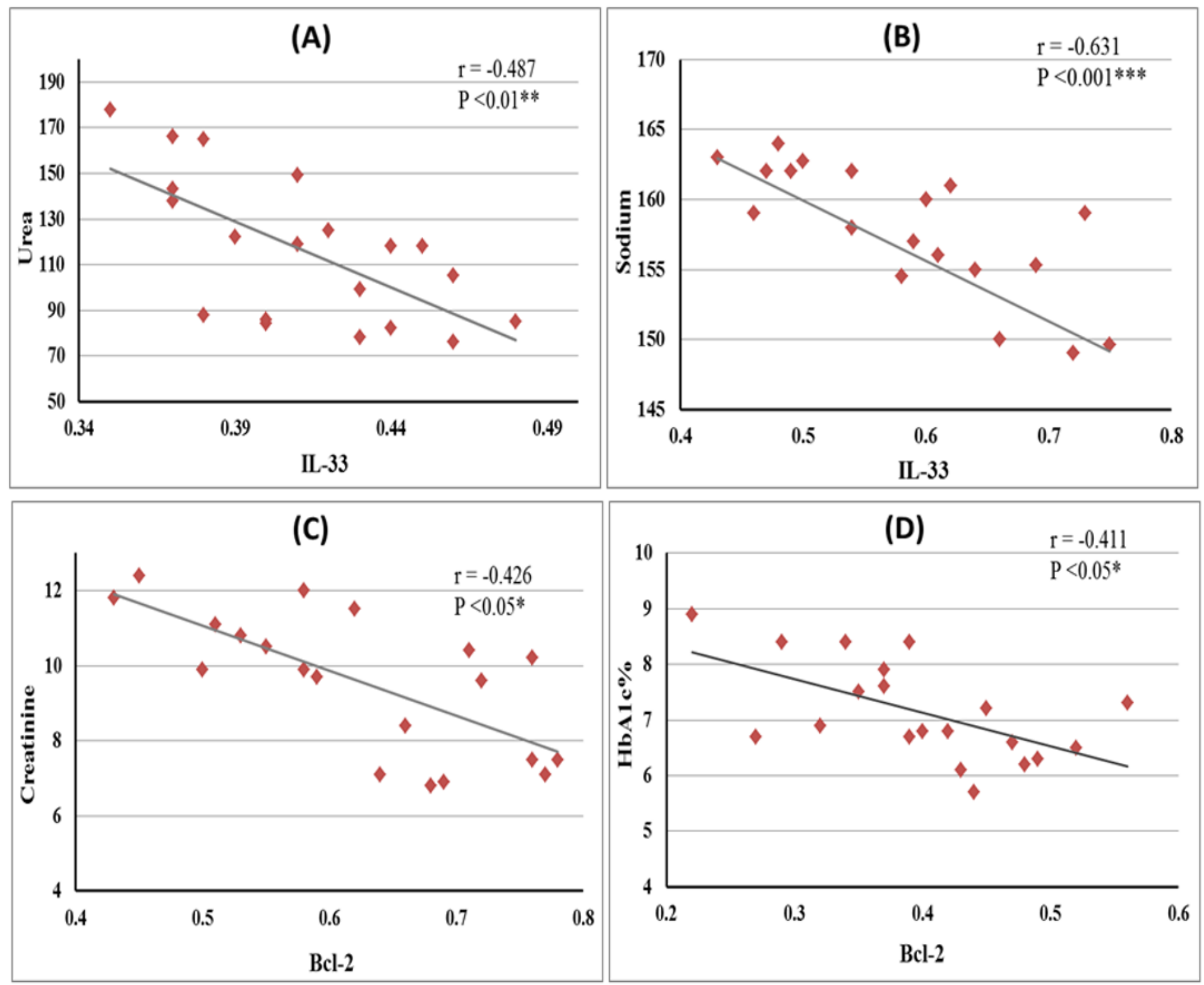

\section{Figure 3}

The correlation between urea with interleukin-33 (A) sodium with interleukin-33 (B) creatinine with beta-cell lymphoma-2 (C) glycated hemoglobin with beta-cell lymphoma-2 among diabetic renal dysfunction groups. Correlation is significant *at $P>0.05$ level, ** at $P>0.01$ level, *** at $P>0.001$ level. 